\title{
O SABER FAZER ESCOLHAS BEM INFORMADAS E A GESTÃO BIOPOLÍTICA DOS CONSUMIDORES NA CONTEMPORANEIDADE
}

\section{THE KNOWLEDGE TO MAKE INFORMED CHOICES AND THE CONSUMER BIOPOLITICAL MANAGEMENT IN CONTEMPORANEITY}

\author{
Andresa Silva da Costa Mutz ${ }^{1}$ \\ Raquel Salcedo Gomes ${ }^{2}$
}

\section{RESUMO}

Examinamos o modo como tem sido operacionalizada a educação financeira, instituída como Política Pública do Estado brasileiro pelo Decreto Federal 7.397/2010, atentando para seus efeitos na constituição dos sujeitos de consumo na contemporaneidade. Selecionamos: I) o depoimento de um membro do grupo de autoajuda conhecido como Devedores Anônimos; II) o teste em um folheto disponibilizado pela Fundação de Proteção e Defesa do Consumidor (PROCON); III) o manual de Prevenção e tratamento do superendividado, editado pela Escola Nacional de Defesa do Consumidor. O referencial teórico adotado na pesquisa é o pósestruturalista e de inspiração foucaultiana. A metodologia empregada na produção e análise dos dados envolve a operação com noções como tecnologia do eu, governo, risco, entre outras. Os resultados obtidos permitiram o mapeamento de três ações - o narrar-se, o julgar-se, o dominarse - requeridas dos indivíduos envolvidos nas atividades pedagógicas promovidas pela Estratégia Nacional de Educação Financeira. Pudemos inferir que as diferentes estratégias relacionadas à consciência para o consumo podem ser compreendidas como modos de conduzir a conduta dos consumidores tornando-os sujeitos confessantes - forma de instrumentalizá-los para o autogoverno.

Palavras-chave: Educação Financeira; Sujeito Consumidor; Tecnologias do Eu.

\section{ABSTRACT}

We examine the way in which financial education, instituted as Public Policy of the Brazilian State by Federal Decree 7.397 / 2010, has been operationalized, paying attention to its effects on the constitution of consumption subjects in the contemporary world. We have selected: I) the testimony of a member of the self-help group known as Anonymous Debtors; II) the test available in a leaflet provided by the Foundation for Consumer Protection and Defense (PROCON); III) the manual of Prevention and treatment of the over-indebtedness edited by the National School of Consumer Protection. The theoretical framework adopted in the research is poststructuralist and of Foucaultian inspiration. The methodology used in the production and analysis of the data involves the operation with notions such as technology of the self, government, risk, among others. The results obtained allowed the mapping of three actions the narrating, the judging, the mastering - required of the individuals involved in the pedagogical activities promoted by the National Strategy of Financial Education. We could infer that different strategies related to consumer consciousness can be understood as ways of conducting consumer behavior by making them confessional subjects - a way of instrumentalizing them for self-government.

Key words: Financial education; Consumer Subject; Technologies of the Self.

\footnotetext{
1 Doutora em Educação, Professora do Departamento Interdisciplinar da Universidade Federal do Rio Grande do Sul - UFRGS. desacost@gmail.com

${ }^{2}$ Doutora em Linguística Aplicada e Informática na Educação, Professora do Departamento Interdisciplinar da Universidade Federal do Rio Grande do Sul - UFRGS. salcedogomes@gmail.com
} 


\section{INTRODUÇÃO}

O sujeito consumidor atualmente é tomado como objeto de saber por diferentes áreas do conhecimento como a neuroeconomia e o neuromarketing ${ }^{3}$. No Brasil, tem sido investido de direitos e deveres por inúmeras instituições que integram o chamado Sistema Nacional de Defesa do Consumidor (SNDC), como Procons, Ministério Público, Defensoria Pública e entidades civis de defesa do consumidor, que atuam de forma articulada e integrada com a Secretaria Nacional do Consumidor (Senacon). Proliferam também pesquisas estatísticas que perscrutam seu comportamento em instituições privadas, como Serasa Experian ${ }^{4}$.

Todos esses exemplos apontam para um grande interesse que instituições de caráter público e privado demonstram ter sobre o comportamento do consumidor. Não somente pela centralidade que o consumo tem ocupado em nossa sociedade (BAUMAN, 2008) mas, principalmente, pelo risco que condutas inadequadas de compra e obtenção de crédito representam na conjuntura econômica atual do capitalismo globalizado. Nas palavras de Ewald (1993):

Na segurança, o termo risco não designa nem um acontecimento nem mesmo um tipo de acontecimento da realidade - os acontecimentos 'funestos' - mas um modo de tratamento específico de certos acontecimentos que podem suceder a um grupo de indivíduos, ou mais exatamente a valores ou capitais possuídos ou representados por uma coletividade de indivíduos, ou seja, por uma população (p. 88)

Com isso, enfatiza-se aqui o caráter social, datado, contingente daquilo que uma determinada sociedade entende por risco. Necessário sublinhar que isso implica aceitar também o caráter social, datado e contingente do tipo de intervenção que cada grupo adotará sobre determinado fenômeno de risco.

Isso converge diretamente para o objeto de estudo nesta pesquisa, que está relacionado com as especificidades do modo como lida-se com os sujeitos "em risco" no interior de Sociedade de Consumidores. Um modo muito contingente de intervenção verificado nas últimas três décadas no País. Tal modo envolve: 1) a objetivação desses sujeitos, conferindo-lhes visibilidade como problema político e 2) a proposição de estratégias de condução da conduta dos mesmos em direção ao que se pressuponha um comportamento de consumo adequado.

O narrar-se e o julgar-se, uma vez que contribuiriam para o exercício do autodomínio, apareceram nomeados nos materiais investigados como estratégias que

\footnotetext{
${ }^{3}$ Para obter mais informações sobre tais ciências, consultar Pradeep (2012) em O cérebro consumista.

${ }^{4}$ Nos referimos às avaliações que resultam em documentos como "Indicador Serasa Experian Qualidade de Crédito do Consumidor".
} 
fortalecem a cidadania e contribuem para a tomada de decisões de consumo, ditas, mais conscientes e são, ao mesmo tempo, entendidos aqui como tecnologias do eu, pois "quando falava em tecnologias do eu, Foucault referia-se a todo este conjunto de técnicas performativas de poder que incitaram o sujeito a agir e operar modificações sobre a sua alma e seu corpo, pensamento e conduta" (RAMOS DO Ó, 2011, p. 175).

Essa “administração do eu” contemporâneo, segundo Rose (1998), pode ser caracterizada pela incorporação das capacidades pessoais e subjetivas no horizonte de interesses dos poderes públicos. A tarefa, ensejada por diferentes instituições sociais, prolifera na contemporaneidade por meio de diversificadas estratégias “(...) para alterar a pessoa visível através de uma ação exercida sobre o invisível mundo interior" (ROSE, 1998, p. 30) e pode ser considerada uma evidência da centralidade atual, ocupada pela chamada expertise da subjetividade. Também pode ser entendida como evidência de um desejo de governo sobre a conduta dos consumidores considerando que "governar (...) é estruturar o eventual campo de ação dos outros" (FOUCAULT, 1995, p. 245).

Aqui se encontra o principal argumento que este artigo defende. A interpretação do ato de representar os consumidores e procurar intervir sobre suas condutas como uma ação de governo. A intenção com isso é desnaturalizar o consumo. Acredita-se que, neste ponto, resida o potencial político da investigação ora apresentada.

\section{ALGUNS ESCLARECIMENTOS TEÓRICO-METODOLÓGICOS}

Wortmann (2001, p. 156) explicita o sentido que se toma para representação ao afirmar que ela "participa da constituição das coisas, não sendo vista como um mero reflexo dos eventos que se processam no mundo". À essa noção de que a representação não apenas descreve a realidade, mas que também a constitui, soma-se a afirmação de Costa (2004, p. 77), de que "quem tem o poder de narrar o outro, dizendo como está constituído, como funciona, que atributos possui, é quem dá as cartas na representação, ou seja, é quem estabelece o que tem ou não tem estatuto de 'realidade"'.

Quanto ao uso do conceito governo, faz-se filiado ao pensamento de Rose e Miller (2012). Toma-se governo como um conjunto de procedimentos que buscam representar determinadas populações e intervir sobre elas, conduzindo suas condutas em um horizonte possível de escolhas. É justamente esse esforço de representação, próprio do governo, que implica que este artigo (e a pesquisa a que se associa) esteja focado na linguagem e no discurso. 
Quanto ao seu papel de intervenção, interessa analisar o modo como as tecnologias de governo alinham a economia e a conduta social aos objetivos sociopolíticos. Entendendo, conforme Rose e Miller (2012, p.46), que o termo tecnologias é usado

a fim de insinuar uma abordagem particular de análise da atividade de governar, um enfoque que presta grande atenção aos mecanismos através dos quais autoridades de vários matizes têm buscado modelar, normalizar e instrumentalizar a conduta, o pensamento, as decisões e as aspirações dos outros, a fim de alcançar os objetivos que eles consideram desejáveis.

Partindo de pressupostos foucaultianos, entende-se que estamos vivendo um momento histórico marcado por uma ênfase biopolítica no governo das populações. Disso decorrem algumas características específicas de nosso tempo, em que as relações de poder têm como alvo o controle da população; o centro de autoridade se dissemina ao longo de diferentes instituições do Estado e também para além dele; prevalece a liberdade do indivíduo e o desafio é conduzir a conduta de todos e de cada em um horizonte de escolhas possíveis. "Governar, nesse sentido, é estruturar o eventual campo de ação dos outros” (FOUCAULT, 1995, p. 245).

Como multiplicidade de indivíduos, uma população apresenta uma diversidade de fenômenos de efeitos econômicos, sociais e políticos. A observação de tais fenômenos se dá a partir das formas como na coletividade eles acontecem e importa acompanhar a aleatoriedade e a duração de cada um dos seus fenômenos. Daí resulta uma multiplicidade de intervenções, pautada por complexas relações de poder, que intentam conduzir a conduta dos consumidores, como se pretende demostrar com essa pesquisa, aproximando-os a essa média considerada desejável para que se garanta o pleno funcionamento do capitalismo atual.

Por isso, pretende-se investigar aqui um conjunto heterogêneo de artefatos culturais que ensinam como consumir mais e melhor, que prescrevem modos adequados de se consumir sem esgotarmos o Planeta. Entende-se que a inclusão do consumo no currículo escolar como tema transversal e na agenda de compromissos políticos do Estado brasileiro na forma de um programa institucionalizado, lhe confere caráter de dispositivo pedagógico, pois o mesmo pressupõe, segundo (LARROSA, 1994, p. 57), “(...) qualquer lugar no qual se constitui ou se transforma a experiência de si. Qualquer lugar no qual se aprendem ou se modificam as relações que o sujeito estabelece consigo mesmo".

Com isso o autor concebe uma noção de educação para além do ambiente institucionalizado da escola. Se considerarmos que é na cultura que se dão as lutas por significação, levando em conta o que afirma Veiga-Neto (2004) "Por que a cultura está imbricada indissoluvelmente com relações de poder, derivam dessas relações a significação do que realmente é relevante culturalmente para cada grupo" (p. 40, grifo meu), então podemos 
entender seu caráter pedagógico, na medida em que tais lutas e embates acabam conferindo legitimidade a determinados modos de ser sujeito em detrimento de outros.

\section{EDUCAÇÃO PARA O CONSUMO, UM ACONTECIMENTO SINGULAR NA HISTÓRIA CONTEMPORÂNEA}

Importa, de imediato, demarcar a singularidade histórica do momento que estamos vivendo para, então, mapear as condições de emergência da educação para o consumo, nosso objeto de estudo nessa pesquisa.

A educação para o consumo no Brasil tem como marco histórico a Lei nº 7.397 de 2010 quando, por decreto presidencial, foi criada a Estratégia Nacional de Educação Financeira - ENEF. Os planos, programas, ações, coordenação e execução da Política Pública em questão ficaram a cargo do Comitê Nacional de Educação Financeira - CONEF, composto, entre outros, por representantes do Banco Central; da Comissão de Valores Mobiliários; da Superintendência de Seguros Privados; dos Ministérios da Fazenda, da Educação, da Previdência Social e da Justiça. Para assessorar esse Comitê em temas relacionados com a educação financeira e previdenciária foi instituído o Grupo de Apoio Pedagógico - GAP, presidido por representante do Ministério da Educação.

Em 5 de maio de 2011, o CONEF aprovou o Plano Diretor que consolidava a ENEF, tornando públicas as primeiras disposições que dariam forma à política pública de educação para o consumo no Brasil. Entre elas, a promoção de uma pesquisa em âmbito nacional para mensurar o grau de educação financeira da população; o lançamento de um site que, além de divulgar a ENEF, permitiu realizar um inventário das ações de educação financeira em andamento no País; um levantamento das experiências internacionais; e, finalmente, as orientações para a implementação da educação financeira nas escolas e para os adultos.

Um projeto piloto da ENEF foi aplicado em 891 escolas públicas de Ensino Médio, de seis unidades de federação, nos dois primeiros anos de existência da Política Pública. E, a partir de 2013, foram criados livros didáticos que, incialmente foram distribuídos no Ensino Médio e, mais recentemente, para os alunos do Ensino Fundamental. Em maio de 2014, foi lançada a Plataforma Aberta de acesso aos livros de educação financeira, em que é possível fazer download da coleção completa, inclusive dos livros para professores que acompanham cada exemplar do aluno.

Em 21 de novembro de 2013, o CONEF deliberou acerca da criação da chamada Semana Nacional da Educação Financeira, na intenção de promover eventos educativos presenciais ou online, atualmente em sua $3^{a}$ edição. 
Para conhecer os resultados do projeto piloto aplicado no Ensino Médio, o Banco Mundial produziu, em 2012, um estudo que resultou no documento intitulado "O impacto da educação financeira no Ensino Médio no Brasil". E, desde outubro de 2014, outro Plano Piloto tem sido aplicado em duas cidades brasileiras em escolas de Ensino Fundamental e são, igualmente, acompanhados pelo Banco Mundial.

Mais recentemente, em novembro de 2015, o CONEF criou o SELO ENEF para certificar as iniciativas de educação financeira que efetivamente contribuem com a consolidação da educação financeira no País.

Finalmente, atendendo a normativa legal, qual seja, o Decreto 7.397/2010, a Base Nacional Comum Curricular, para o Ensino Infantil, Fundamental e Médio, igualmente contempla em menor e maior grau a Educação Financeira, entendendo-a como sinônimo de educação para o consumo.

Procurou-se, até aqui, demarcar a singularidade histórica do momento que se vive para então mapear, ainda que sucintamente, as condições de emergência da educação para o consumo no Brasil.

Entende-se que a coexistência, por vezes ambivalente, entre o império do efêmero (LIPOVETSKY, 2009) que nos convoca ao consumo excessivo e descarte imediato, e um conjunto de enunciados que apelam para um modo de ser sujeito consumidor marcado pelas noções de economia, uso racional dos recursos econômicos e naturais, submissão dos desejos à reflexão e ao planejamento das compras, interesse pelo futuro e pela coletividade, é um acontecimento que merece nossa atenção. Foucault (2003) explica que

As forças que se encontram em jogo na história não obedecem nem a uma destinação, nem a uma mecânica, mas ao acaso da luta. Elas não se manifestam como formas sucessivas de uma intenção primordial; como também não têm o aspecto de um resultado. Elas aparecem sempre na área singular do acontecimento (p. 28).

Assim, as transformações políticas, econômicas e sociais decorrentes do papel cada vez mais centralizador que o consumo ocupa em nossas vidas na Sociedade de Consumo (BAUDRILLARD, 2007) e o impacto dessas transformações nos tipos de conexões verificadas entre o consumidor $\mathrm{e}$ as mercadorias, da qual resultam a Cultura de Consumo (FEATHERSTONE, 1995) justificam o uso do termo acontecimento para nos referirmos ao surgimento dessa "urgência" por educação para o consumo, nomeada nos documentos que temos analisado como Educação Financeira.

Importa ainda acrescentar que outra característica peculiar desse tempo em que estamos vivendo é o fato de a lógica da empresa se espalhar pelo corpo social e subjetivar o 
trabalhador, transformando-o em empresário de si. Destaca-se essa marca da contemporaneidade porque espera-se encontrar ao final do trabalho de pesquisa elementos que permitam estabelecer uma relação entre esta marca cultural da pós-modernidade, - que é o consumo, e esta prática de governo, - o empresariado de si, segundo aquilo que já nos alertara Foucault (2008), de que “(...) deve-se considerar o consumo como uma atividade empresarial pela qual o indivíduo, a partir de um certo capital de que dispõe, vai produzir uma coisa que vai ser sua própria satisfação" (p. 311).

\section{NARRAR-SE}

$\mathrm{O}$ ato de narrar-se, como veremos nesta seção, opera no sentido de ver-se e expressar-se também, pois exige do indivíduo um exercício de reflexão e de exteriorização. Segundo Larrosa (1994), “(...) tendemos a pensar o conhecimento em termos de visão de si mesmo" (p. 58), nesse caso, "o autoconhecimento é algo assim como um voltar o olho da mente para dentro" (p. 59). Há, em nossa sociedade, uma instituição que oportuniza ao indivíduo, no interior de um ritual bem estruturado, um tempo e um espaço para que se constitua como sujeito de consumo consciente através do exercício da autonarrativa: trata-se do grupo de Devedores Anônimos 5 .

O primeiro passo para a cura da doença do superendividamento, segundo a lógica do grupo D. A., seria a confissão da situação em que se encontra o consumidor em relação às suas economias. O teste do D.A. envolve o escrutínio sobre as ações do sujeito pela confissão e envolve, especialmente no caso do superendividamento, questões relativas aos hábitos de consumo dos sujeitos. A especificidade do teste do D.A., por exemplo, disponibilizado nos sites dos grupos espalhados por todo o Brasil, se encontra na mobilização da 'interioridade' dos indivíduos para resolverem as questões, na medida em que as perguntas envolvem a mensuração de sentimentos e emoções, como:

O seu débito está tornando a sua vida familiar infeliz?6,

Seus débitos fazem você pensar menos de você mesmo?

Você tem medo que o seu patrão, família ou amigos venham a saber da extensão total de suas dívidas?

Quando você se depara com uma dificuldade financeira, o prospecto de uma Financeira Ihe dá uma sensação de alívio? ${ }^{7}$

\footnotetext{
${ }^{5}$ Localizou-se, em pesquisa por site de busca, a existência de Devedores Anônimos nas principais capitais brasileiras. Encontramos também o Grupo D.A. On-line, onde através de um programa de computador, o consumidor pode escolher uma sala virtual de Devedores Anônimos para entrar. Conforme informação disponível em: http://devedoresanonimos.blog.br/daonline/reunioes. Acesso em: 26/4/2015.

${ }^{6}$ Utiliza-se a letra do tipo Calibri tamanho no 10 e espaço de recuo de citação para grafar todos os excertos de materiais analisados. Utilizase esse recurso na intenção de diferenciá-los dos demais trechos em recuo, dedicados à inserção de citações, em que prevalece a letra tipo Times New Roman.

${ }^{7}$ Excertos do teste do endividamento disponibilizado pelo grupo de Devedores Anônimos com sede em Porto Alegre/RS, no seguinte endereço eletrônico: http://devedoresanonimosrs.wordpress.com. Acesso em: 26/4/2015.
} 
Mais uma vez evocamos Larrosa (1998), que se vale de Foucault, para pensar o tema da visibilidade que pressupõe o exercício de narrar-se e subjetivar-se:

Nos trabalhos de Foucault, tanto o objeto quanto o sujeito são variáveis dos regimes de visibilidade e dependem de suas condições. Um regime de visibilidade composto por um conjunto específico de máquinas óticas abre o objeto ao olhar e abre, ao mesmo tempo, o olho que observa. Determina aquilo que se vê ou se faz ver, e o alguém que vê ou faz ver. Por isso o sujeito é uma função da visibilidade, dos dispositivos que o fazem ver e orientam seu olhar. E esses são históricos (p. 61-62).

Assim, considera-se que os Devedores Anônimos compõem uma parte da máquina que torna visível e faz ver o sujeito de consumo. Ao submeter os indivíduos pela confissão no teste acima descrito e no depoimento abaixo apresentado - de suas emoções e sentimentos envolvidos nos atos de compra e crédito, fazem ver um 'eu' do consumo. Um 'eu' interior marcado pelas emoções e sentimentos. O 'eu' do consumo a ser domado, racionalizado, pensado, planejado. Enfim, esse ‘eu’ desejável que assume seu protagonismo como agente de transformação de si mesmo e dos outros. Isto posto, apresenta-se a confissão de Maria, um nome fictício dado a uma das participantes do D.A. com sede em São Paulo, que aceitou deixar gravado em áudio seu depoimento disponibilizado no site do grupo ${ }^{8}$. A seguir, alguns excertos do depoimento de Maria

Sou uma devedora compulsiva. (...) Aí eu fiz um empréstimo e passei vários cheques pré-datados e depois eu comecei a sentir a pressão psicológica, né? Porque eu passava noites e noites sem dormir, pensando como que eu ia fazer para pagar todos aqueles cheques, pensando como que eu ia fazer para sustentar minha família. Aí veio a culpa. A culpa porque eu tinha feito aquilo. Foi quando uma amiga minha me chamou para conhecer a sala do D.A. E eu fui, porque eu não aguentava mais. Era muito desespero, muito sofrimento. Muita pressão psicológica. E quando eu chequei lá...(som de um suspiro). (...)

Eu comecei a falar dos meus problemas. Eu comecei a ser compreendida. Eu comecei a compreender a minha dificuldade com dinheiro. (...)

O desespero passou, a angústia, a tensão. Eu fiz um planejamento. Fiz alívio de pressão. E agora eu estou levando minha vida com responsabilidade. Responsabilidade financeira. Mas eu sei que sozinha eu não consigo. Se eu não frequentar as reuniões, se eu não tiver com os iguais a mim, eu não consigo sozinha. Então a sala me dá força, me dá esperança, me dá direção, né? As pessoas falam de si e eu falo de mim e eu aprendo através das pessoas e elas aprendem através de mim. E é uma troca. Uma troca de experiências, de força, de esperança. Esses traumas, essas coisas afetam, né? E eu não sei lidar com o dinheiro. Então o D. A. me ensina. Todas as reuniões que eu frequento, a literatura. Me ensinam a lidar com o dinheiro de uma forma saudável'?

\footnotetext{
${ }^{8}$ No site do D.A São Paulo, existe um link que nos leva ao canal de vídeos on-line na plataforma YouTube. Lá encontramos cinco arquivos de áudio contendo depoimentos de devedores compulsivos, disponíveis em: https://www.youtube.com/channel/UCUULoR JACk7G98fx2cHfxA. Acesso em: 26/4/2015.

${ }^{9}$ Arquivo em formato de áudio do qual fizemos a transcrição e disponível em: https://www.youtube.com/watch?v=kk4MeSyhrGE. Acesso em: 26/4/2015.
} 
Esse 'eu' construído por "Maria" pela autointerpretação na narrativa "não se constitui em uma relação não-mediada sobre si mesmo" (LARROSA, 1998, p. 70). Antes, "pelo contrário, a narrativa, como modo do discurso, está já estruturada e preexiste ao eu que se conta a si mesmo" (idem). Considerando, como demostrou Foucault, que "as formas legítimas de olhar se relacionam com as formas legítimas de dizer” (LARROSA, 1998, p. 665), então podemos pensar em "Maria" como um exemplo do modo como os sujeitos de consumo consciente emergem no discurso, tornando-se visíveis e dizíveis no interior de uma racionalidade que opera no controle, no gerenciamento, na supervisão e manutenção do equilíbrio entre o 'apelo' ao consumo - pela exploração dos sonhos, dos desejos, das fantasias e 'apelo' ao consumo consciente - pela constituição de um 'eu' consumidor que se reconheça agente de transformações, com competência 'interior' para ser mais organizado, mais racional, mais econômico.

\section{JULGAR-SE}

No domínio da moral, a narrativa de si - como processo mediado que permite ao indivíduo estabelecer certas relações consigo - tem a forma geral do 'julgar-se' e remete à norma, ao dever, à lei. Como ensina Larrosa (1998), essa relação se estabelece porque

\footnotetext{
No âmbito moral, enquanto normativo e jurídico, ver-se, expressar-se e narrar-se se convertem em julgar-se. E julgar-se supõe que se dispõe de um código de leis em função das quais se julga (embora o sujeito seja considerado como autolegislador ou autônomo). Supõe que a pessoa possa converter-se em um caso para si própria, isto é, que se apresente delimitada, na medida em que cai sob a lei ou se conforma à norma (p. 75).
}

No caso do depoimento de confissão da devedora compulsiva, percebemos o modo como vai se subjetivando ao se submeter como caso para os outros. Quando decidiu frequentar o D. A, o fez porque antes já havia se tomado como caso para si mesma. Algum critério, igualmente mediado e contingente, a fez julgar-se 'devedora compulsiva'. O Devedores Anônimos disponibiliza um teste, como já mencionado, respondendo questões que dizem respeito ao comportamento de consumo, em que é possível reconhecer-se como sujeito do consumo segundo critérios de valor normalizados pela sociedade. Nesse sentido, chamou atenção a proliferação de materiais educativos com esses mesmos mecanismos de testagem nas 
instituições do PROCON, órgão responsável nos estados e municípios do Brasil pela Proteção e Defesa do Consumidor ${ }^{10}$.

Inicialmente o folheto ${ }^{11}$ apresenta uma definição de endividamento, como lemos abaixo

Nos últimos anos, houve um crescimento significativo de endividados no Brasil. A expansão da oferta de crédito e a falta de controle do orçamento doméstico torna cada vez mais comum o aparecimento de consumidores impossibilitados de pagar suas dívidas. Quando isto acontece, o consumidor se torna SUPERENDIVIDADO (gasta mais do que ganha todos os meses) (PROCON/ES, Folheto Superendividamento, p. 2, grifos nossos)

A estratégia de autoexame, materializada no teste que segue, intitulado Estou superendividado?, como se pode verificar no folheto em análise, remete à dimensão moral do governo da conduta dos consumidores, na medida em que cada consumidor, ao ler o texto e se examinar, o fará de acordo com padrões e valores culturalmente instituídos e tomados como normais. Pois, como lembra Larrosa (1998, p. 6), “o normal se converte em um critério que julga e que valoriza negativa ou positivamente. E no princípio de um conjunto de práticas de normalização cujo objetivo é a produção do normal".

O tipo do conhecimento sobre si requerido pelo mecanismo do teste do PROCON remete à necessidade de organização e inscrição de dados, por parte dos consumidores, em relação ao volume de rendimentos, total dos custos com créditos na porcentagem geral de rendimentos, planejamento a longo e curto prazo das compras, elaboração de planilhas com datas de vencimento. Todo esse aparato de registro dos hábitos de compra acaba por também governar a conduta dos envolvidos em tais operações, pois como afirmam Miller e Rose (2012, p. 87) "fazer com que as pessoas registrem coisas e as contem (...) é em si mesmo um modo de governá-las, um estímulo a que os indivíduos interpretem suas vidas de acordo com tais normas".

Observando a estrutura do teste, pode-se perceber em cada pergunta que as respostas obedecem sempre a uma mesma gradação, não estão misturadas. Assim as respostas (A) remeterão, ao final, a um tipo de consumidor "mais consciente" e as respostas (D) remeterão ao tipo de consumidor "menos consciente". Os dois extremos da norma, portanto, remetem a essas duas categorias. Sobre os que marcaram (A) na maioria das respostas se disse "você poderá se transformar em um grande investidor" (PROCON/ES, Folheto Superendividamento,

\footnotetext{
${ }^{10}$ Chegou-se até folheto informativo sobre o superendividamento produzido pelo PROCON do estado brasileiro do Espírito Santo quando examinei cada um dos sites de PROCONs das capitais do País. Foi possível encontrar outros manuais de educação para o consumo, semelhantes a esse em questão, no PROCON do Rio Grande do Sul, de São Paulo, do Paraná, do Distrito Federal, do Pará, de Pernambuco e de Minas Gerais. Optou-se por esse produzido no PROCON do estado do Espírito Santo por ser o que mais explicitamente se endereçava aos endividados e superendividados.

${ }^{11}$ Disponível em: http://www.procon.es.gov.br/download/FolhetoSuperendividamento.pdf. Acesso em: 26/4/2015.
} 
p. 7). No outro extremo, igualmente capturados pela norma, estão os que mais marcaram a letra (D). Sobre eles se disse: "Você está muito encrencado" e "Procure ajuda especializada, crie um planejamento para sair dessa situação e não desista. Endividamento é um processo, romper com ele também!” (PROCON/ES, Folheto Superendividamento, p. 8).

Para os normalizados, ou seja, para os que marcaram mais as letras (B) ou (C), os que estão na média, pois medir é comparar, se disse

(B) Fique tranquilo. Caso você esteja enfrentando uma situação de endividamento, provavelmente será passageiro. Embora você cometa alguns "deslizes", você se enquadra no perfil do endividado passivo. Endividamento passivo é aquele causado por algum imprevisto, alheio à sua vontade. Mesmo assim, é importante que você amplie seu conhecimento em relação às finanças para fazer seus rendimentos se multiplicarem e evitar ficar à mercê de situações que podem ser prevenidas (PROCON/ES, Folheto Superendividamento, p. 7, grifo nosso).

(C)Muito cuidado. Seu grau de endividamento é elevado e você está lidando com sua vida financeira de um modo arriscado. Seu conceito de imprevisto está equivocado e você se enquadra na categoria de endividado ativo, ou seja, ativamente você se envolve em alguma situação de endividamento. Você precisa rever urgente a forma com que está gerindo seus rendimentos e buscar instrução financeira. Além disso, é fundamental analisar quais são as motivações que levam você ao endividamento constante. '́ muito possível que alguma questão afetiva, consciente ou inconscientemente, esteja interferindo na sua relação com o dinheiro (PROCON/ES, Folheto Superendividamento, p. 8, grifo nosso).

Assim, o sujeito de consumo da média, ou um consumidor considerado normal, é alguém que está sempre ampliando seus conhecimentos em relação às finanças. Tem dívidas, mas as mantêm sobre controle. E se percebe que está ultrapassando limites e que as dívidas podem se tornar impagáveis, busca entender e julgar as motivações interiores que o levam a viver assim para transformar-se e contornar o problema.

\section{DOMINAR-SE}

Prevenção e tratamento do superendividado ${ }^{12}$ é o primeiro volume de uma coleção criada pela Escola Nacional de Defesa do Consumidor em parceria com o Ministério da Justiça, a Secretaria do Direito Econômico e o Departamento de Proteção e Defesa do Consumidor. No prefácio de tal manual lemos

O superendividamento é fonte de isolamento, de marginalização; ele contribui para o aniquilamento social do indivíduo. Quanto mais este fenômeno aumenta, mais seu custo social se eleva e mais a necessidade de combatê-lo se impõe (MARQUES, LIMA e BERTONCELLO, 2010, p.10, grifos nossos).

\footnotetext{
${ }^{12}$ Marques, Lima e Bertoncello, 2010.
} 
A questão mais geral, portanto, que envolve o manual é o tratamento do superendividamento. O prefixo super, aqui, faz muita diferença. A construção discursiva, que enuncia o consumo como problema está marcada por duas linhas aparentemente contraditórias, mas que convergem a um mesmo ponto. Uma alerta para os cuidados com as dívidas por conta do risco do superendividamento e sublinha, portanto, seus resultados nefastos para o indivíduo. Outra linha de força aponta para o crédito como acesso ao consumo, solução para os mais diversos problemas da humanidade, mecanismo de inclusão, enfim, um enunciado que opera na construção do homem endividado pela naturalização da dívida, na medida em que tem sido considerado um "fato inerente à vida", como se pode ler abaixo no Manual

\begin{abstract}
O endividamento ou ter alguma dívida frente a um fornecedor (supermercado, banco, cartão de crédito, loja de departamentos, financeira de carros) é um fato inerente à vida na atual sociedade de consumo, faz parte da liberdade das pessoas no mercado de hoje, do ser "consumidor", em qualquer classe social. Efetivamente, para consumir produtos e de serviços, essenciais ou não, os consumidores estão quase todos - constantemente endividando-se, e criando um "passivo" de dívidas que devemos mês a mês fazer frente com nosso orçamento familiar e patrimônio (nosso "ativo", se pensarmos em termos de planejamento financeiro) (MARQUES, LIMA e BERTONCELLO, 2010, p.17, grifos nossos).
\end{abstract}

Assim, a narrativa que estabelece o excesso de dívidas ou o superendividamento, como uma anormalidade prevê, ao mesmo tempo, a normalidade do endividamento. $\mathrm{O}$ que complementa o argumento de Lazzarato (2012) de que o governo sobre a população de devedores se dá à distância pelo controle de suas condutas que devem se ajustar para ser compatíveis com o pagamento dos seus débitos.

O enunciado que relaciona a liberdade de escolha dos consumidores, bem tão caro ao capitalismo liberal, é (re)significado no neoliberalismo, acentuando-se a responsabilização dos indivíduos e a necessidade de aprender a escolher. Sobre isso, Bauman (2008) sublinha que "uma regra central e amplamente incontestada, já que não escrita, de uma sociedade de consumo é que ser livre para escolher exige competência: conhecimento, habilidades e determinação para usar tal poder” (p. 174).

Por isso a necessidade de Políticas Públicas como a ENEF (Brasil) que, ao operarem sobre segmentos da população que são considerados de risco, buscam "educar e formar autossuficiência e autonomia nos indivíduos" (LOPES, 2011, p. 296), capacitando-os com conhecimentos que lhes permitam comprar bem - que saibam fazer escolhas que convencionamos adequadas para que continuem comprando sempre - ou seja, que por meio da informação, permaneçam habilitados por mais a escolher, como lemos a seguir 
O maior instrumento de prevenção do superendividamento dos consumidores é a informação. Informação detalhada ao consumidor é um dever de boa-fé, dever de informar os elementos principais e mesmo dever de esclarecer o leigo sobre os riscos do crédito e o comprometimento futuro de sua renda (MARQUES, LIMA e BERTONCELLO, 2010, p.26, grifos nossos).

O caráter pedagógico dessa informação que esclarece e responsabiliza (AQUINO, 2011) localiza, nesse caso, os recursos de prevenção e tratamento do superendividamento como um esforço do governo da conduta em fazer emergir o consumidor autônomo, auto-governável, que tenha condições de dominar-se.

Pelo que se pode perceber na análise do Manual, o ritual de renegociação entre devedores e credores faz parte da estratégia pedagógica do Judiciário para prevenir e tratar o superendividamento

(...) este sistema requer dos devedores um aprendizado ativo sobre as consequências, custos e responsabilidade em fazer empréstimos em demasia, o que também estimula os credores na composição amigável dos litígios, se valorizado o esforço dos devedores no cumprimento de suas obrigações. Este aprendizado ativo encontra seu ápice na audiência de renegociação, para a qual são convidados todos os credores e o consumidor, que são esclarecidos acerca do fenômeno social do superendividamento e suas repercussões, sendo instados a encontrar uma alternativa para que o devedor consiga, dentro de suas possibilidades, honrar suas obrigações. (MARQUES, LIMA e BERTONCELLO, 2010, p. 64, grifos nossos).

O ritual de audiência no judiciário submete o consumidor e as empresas à condição de réu e acusador, respectivamente. Determina, em outras palavras, a condição do sujeito de consumo como um réu passível de culpa. A Justiça, nesse cenário, para além de sua função de dirimir conflitos, tem uma função curativa, reformadora, expiatória, por isso, junto à pena, propõe um remédio eficaz para a doença do consumo, um 'medicamento' que causa melhoras percebidas por todo o tecido social, como o retorno do consumidor às compras em vista de que o acusador, satisfeito com a pena, retira a queixa e exclui o consumidor do cadastro de inadimplentes, dando-lhe oportunidade de ser livre novamente. Para que se evite a reincidência no endividamento, o consumidor é encaminhado para setores especializados que vão instrumentalizá-lo, em oficinas de Orçamento Familiar, com modos mais eficientes de dominarse a si mesmo em direção a um modelo de consumo desejável, o consumo consciente. Nas palavras das autoras do Manual:

A oficina pretende apoiar estes hipervulneráveis ensinando-lhes a administrar esses sentimentos e, sobretudo, construir em conjunto alternativas viáveis e fundamentadas juridicamente para resolver a grave condição econômico-financeira superando preconceito moral via de regra presente nestas circunstâncias (MARQUES, LIMA e BERTONCELLO, 2010, p.13, grifos nossos).

A partir de Foucault, compreende-se como, nas práticas discursivas e não discursivas implicadas nesse emaranhado de instituições, leis, espaços arquitetônicos, rituais - 
para usar como exemplo apenas os casos aqui analisados - os indivíduos se constituem sujeitos de consumo. Nesse sentido, "aprender a ver-se, a dizer-se, ou a julgar-se é aprender a fabricar o próprio duplo. E a sujeitar-se a ele" (LARROSA, 1998, p. 80). Principalmente porque, como sublinha Lazzarato (2011, p. 18), no neoliberalismo, “o mercado e a concorrência não são produtos naturais e automáticos (...) é preciso intervir, e intervir muito (...) para que os frágeis mecanismos da concorrência possam funcionar".

\section{TECNOLOGIAS CONTEMPORÂNEAS DE GOVERNO DOS CONSUMIDORES}

Procurou-se evidenciar a noção de que o consumo tem sido objetivado como problema de governo da conduta na democracia neoliberal não apenas porque diz respeito à subjetividade dos consumidores, mas também pelas implicações políticas e econômicas dele decorrentes. Inferiu-se que as diferentes estratégias relacionadas à consciência para o consumo podem ser compreendidas como modos de conduzir a conduta dos consumidores tornando-os sujeitos confessantes e também como forma de instrumentalizá-los para o autogoverno.

Ao longo da análise, foi possível perceber que as diferentes estratégias pedagógicas ensejadas pela política em questão apontavam para o "saber fazer escolhas bem informadas" como um grande objetivo a ser alcançado pelos sujeitos nela envolvidos. O que permite afirmar que prevalece, nessa Política Pública, um tipo de informação que esclarece ao mesmo tempo em que responsabiliza. Isso, a nosso ver, é indício de uma intencionalidade - a gestão biopolítica dos consumidores, que atende a uma demanda ou urgência contemporânea, qual seja, a manutenção do consumo em tempos marcados por crises econômicas locais e globais.

Nesse sentido, justifica-se termos apresentado neste artigo os exercícios de narrarse e julgar-se como condições de existência para que o jogo do poder resulte no dominar-se dos consumidores. Nas palavras de Larrosa (1998, p. 79), “O poder, para afetar, traz à luz, fala e obriga a falar, julgar. O ver, o dizer, e o julgar são, desse ponto de vista, parte das operações de constituição do que é afetado.

Quanto aos efeitos dessa Política Pública na constituição dos sujeitos de consumo, verificou-se que as estratégias analisadas acabaram por legitimar um modo de vida à crédito, para usar uma expressão de Zygmunt Baumann (2010). Foi possível verificar ainda que tais estratégias concorrem para a naturalização do consumo, podendo ser entendidas mais como recurso de controle das condutas para manter em funcionamento o sistema econômico em vigor do que uma tomada de posição crítica ao modelo de consumo que tem causado também prejuízos ao meio ambiente, à qualidade de vida dos indivíduos e a muitas relações sociais. 


\section{Referências}

AQUINO, Julio Groppa. A governamentalidade como plataforma analítica para os estudos educacionais: a centralidade da problematização da liberdade. In: Foucault: filosofia \& política. BRANCO, Guilherme Castelo; VEIGA-NETO, Alfredo (orgs.) Belo Horizonte: Autêntica Editora, 2011, p. 195-211.

BAUDRILLARD, Jean. A sociedade de consumo. Brasil: Edições 70, 2007.

BAUMAN, Zygmunt. Vida para consumo: a transformação das pessoas em mercadorias. MEDEIROS, Carlos Alberto (trad.). Rio de Janeiro: Jorge Zahar, 2008.

BAUMAN, Zygmunt. Vida a crédito: conversas com Citlali Rovirosa-Madrazo. WERNECK, Alexandre (trad.). Rio de Janeiro: Jorge Zahar, 2010.

EWALD, François. Foucault, a Norma e o Direito. António Fernando Cascais (trad.). Lisboa: Vega, 1993.

FEATHERSTONE, Mike. Cultura de Consumo e Pós-modernismo. Julio Assis Simões. São Paulo: Studio Nobel, 1995.

FOUCAULT, Michel. O sujeito e o poder. In: DREYFUS, Hubert; RABINOW, Paul. Michel Foucault. Uma trajetória filosófica: para além do estruturalismo e da hermenêutica. Rio de Janeiro: Forense Universitária, 1995.

FOUCAULT, Michel. A Ordem do Discurso. Aula inaugural no Collège de France, pronunciada em 2 de dezembro de 1970. SAMPAIO, Laura Fraga de Almeida (trad.). São Paulo: Edições Loyola, 1996.

GALLO, Sílvio. Do cuidado de si como resistência à biopolítica. In: Foucault: filosofia \& política. BRANCO Guilherme Castelo; VEIGA-NETO Alfredo (org.) Belo Horizonte: Autêntica Editora, 2011, p.371-391.

LARROSA, Jorge. Tecnologias do Eu e a Educação. In: SILVA, Tomaz Tadeu (org). O Sujeito da Educação: Estudos Foucaultianos. Petrópolis: Editora Vozes, 1994, p. 35-86.

LARROSA, Jorge. Pedagogia Profana: danças, piruetas e mascaradas. VEIGA-NETO, Alfredo (trad.). Belo Horizonte: Autêntica, 2006.

LAZZARATO, Maurizio. O governo das desigualdades: crítica da insegurança neoliberal. SANTOS, Renato Abramowicz (trad.) São Carlos: EdUFSCar, 2011.

LIPOVETSKY, Gilles. O império do efêmero: a moda e seu destino nas sociedades modernas. Maria Lúcia Machado (trad.). São Paulo: Companhia das Letras, 2009.

LOPES, Maura Corcini. Norma, inclusão e governamentalidade neoliberal. In: Foucault: filosofia \& política. BRANCO, Guilherme Castelo; VEIGA-NETO, Alfredo (org.) Belo Horizonte: Autêntica Editora, 2011, p. 283-298.

MARQUES, Cláudia Lima; LIMA, Clarissa Costa de; BERTONCELLO, Karen Rick Danilevicz. Prevenção e tratamento do superendividamento. Brasília: Ministério da Justiça - Secretaria de Direito Econômico - Departamento de Defesa e Proteção do Consumidor, 2010.

MILLER, Peter. ROSE, Nikolas; Governando o presente: gerenciamento da vida econômica, social e pessoal. VALÉRIO, Paulo Ferreira (trad.). São Paulo: Paulus, 2012. 
RAMOS DO Ó, Jorge. Tecnologias de subjetivação no processo histórico de transformação da criança em aluno a partir de finais do século XIX. In: Foucault: filosofia \& política. BRANCO Guilherme Castelo; VEIGA-NETO Alfredo (org.) Belo Horizonte: Autêntica Editora, 2011, p.175-194.

ROSE, Nikolas. Governando a alma: a formação do eu privado. In: SILVA, Tomaz T. (org.) Liberdades Reguladas: a pedagogia construtivista e outras formas de governo do eu. Petrópolis: Vozes, 1998.

WORTMANN, Maria Lúcia C. O uso do termo representação na educação em ciências e nos estudos culturais. Pro-Posições, 12(1), 2001, p. 151-161.

VEIGA-NETO, Alfredo. Educação e governamentalidade neoliberal: novos dispositivos, novas subjetividades. In: Retratos de Foucault. PORTOCARRERO, Vera; Guilherme Castelo BRANCO (orgs.). Rio de Janeiro: Nau, 2000. p. 179 a 215.

Submetido em: 23/05/2019

Aprovado em: 15/06/2019 